\title{
A promoção da autoestima na criança
}

\section{The promotion of self-esteem in children}

\author{
Cecília Frada*, Ivone Neves ** \\ * Centro de Caridade Nossa Senhora do Perpétuo Socorro, ** Escola Superior de Educação de Paula \\ Frassinetti e Universidade Lusófona de Humanidades e Tecnologias
}

\begin{abstract}
Resumo
A criança não é o alvo nem o objeto da educação: ela é o único sujeito educativo. Num contexto de uma atividade norteada pela absorção por parte das crianças dos valores como amizade, respeito, responsabilidade e autonomia, foi focalizada uma intervenção ao nível da promoção da autoestima de uma criança de 5 anos. Com os dados recolhidos, pôde aferir-se que a autoestima é um elemento crucial para a formação de uma personalidade sã e para a sua afirmação enquanto cidadã e, concomitantemente, que o educador assume um papel relevante e determinante na educação para a promoção da autoestima.
\end{abstract}

Palavras-Chave: Autoestima, Educação Pré-Escolar, Valores

\begin{abstract}
The child isn't neither the target nor the object of the education: she is the only educational subject. Within a framework of an activity guided by the absorption by children of values like friendship, respect, responsibility and autonomy, an intervention concerning the promotion of a five years old child's self-esteem of a child was focused. With the data collected, it was gauged that self-esteem is a crucial element for the constitution of a sane personality and for his affirmation as a citizen and, concomitantly, that the educator assumes an important and decisive role in education for the promotion of self-esteem.
\end{abstract}

Keywords: Self-esteem, Preschool Education, Values

“O guerreiro sorri - porque não existe nada que o assuste, nem nada que o prenda. Com a segurança de quem sabe o que quer, abre a porta e entra." Paulo

Coelho, 1997

\section{Introdução}

Perceber a importância da autoestima, na idade mais tenra, não é algo intuitivo ou que mereça sequer algum cuidado. "É ainda muito criança", "psicose de adultos", "com a idade vão ver que passa", são alguns dos epítetos ou vãs afirmações desvalorizadoras do tema, que, para a maior parte é até um não assunto. Nada mais errado, todavia.

Se não antes, na idade pré-escolar, em transição para a fase escolar, verificam-se, segundo Freud, grandes transformações que deixam marca para a vida adulta.
Num enquadramento de uma atividade norteada pela absorção por parte das crianças de valores como a amizade, o respeito, a responsabilidade e a autonomia, a promoção da autoestima da criança, que evidencie dela carecer, constitui um pilar basilar para a sua formação.

Tendo em conta este substrato, foi desenvolvido um estudo, em ambiente de ensino pré-escolar, ao longo de um ano lectivo, tendo como sujeito e alvo uma criança dos 5 anos, que revelava níveis extremamente baixos de autoestima. No presente artigo, elaboraremos sobre a metodologia seguida, os resultados alcançados e as principais conclusões extraídas.

Sem embargo e considerações ulteriores, antecipa-se, como grande corolários que, no estudo e investigação efectuados, e utilizando vários instrumentos de investigação, foi possível recolher dados que permitiram aferir que a autoestima é um elemento crucial para a formação de uma personalidade sã e para a sua afirmação enquanto cidadã e, concomitantemente, que o educador assume um papel relevante e determinante na educação para a promoção da autoestima - "Quem tem autoestima, enfrenta o insucesso como uma adversidade, não como uma prova de incapacidade pessoal" (Odete Fachada, 2010).

\section{Metodologia}

Foi adotada a metodologia de estudo de caso, com uma abordagem de natureza qualitativa, com o principal objetivo de perceber a evolução da autoestima da criança e entender de que forma um educador pode ajudar crianças em idade pré-escolar a construírem uma alta autoestima, "especialmente indicado para investigadores isolados, dado que proporciona uma oportunidade para estudar, de uma forma mais ou menos aprofundada, um determinado aspecto de um problema em pouco tempo"Bell (1997:23).

Através da implementação de algumas atividades e outras iniciativas de forma intencional, procurou-se entender e interpretar situações que fossem representativas de uma dimensão basilar no processo de formação pessoal e social da criança, como é a autoestima. 
Foram assim criadas situações reais que pudessem ser paradigmáticas de atitudes, comportamentos ou reações onde se pudesse aquilatar a existência e o grau de autoconfiança e autoestima, para, a partir desses dados, se construir primeiramente um acervo factual relevante e, depois, monitorizar as evoluções e os efeitos das intervenções realizadas ("a aprendizagem é uma construção pessoal levada a cabo pelo aluno, graças à ajuda que recebe de outras pessoas." - Zabala (2001:162).

Deste conjunto progressivo de ações e reações se foram extraindo conclusões e formando convicções para procurar vias de mudanças, centradas sobretudo no estudo da criança em concreto.

Partindo da pertinência do tema, que se era já uma preocupação intuitiva, mais relevância assumiu perante a constatação da pela existência de crianças no grupo que apresentavam níveis baixos de autoestima, com efeitos nefastos no seu comportamento e na realização das tarefas que lhes são cometidas, foi colocada a questão orientadora do estudo: de que forma o educador pode ajudar a construir a autoestima de uma criança de 5 anos?

Para seguir o caminho de obtenção de resposta à questão fulcral, foram utilizados instrumentos metodológicos que melhor se adequassem à sua pesquisa e que constituíssem uma recolha de dados o mais completa possível.

Desde logo, a observação. Aqui, teve acuidade o registo de incidentes críticos, através de fotografias, descrições diárias, comportamento em actividades significativas, em ordem a documentar eventuais mudanças ou evoluções.

Recorreu-se também a uma entrevista semiestruturada à Educadora da sala dos 5 anos. Concedendo-se embora liberdade ao entrevistado, em que as perguntas-guia eram relativamente abertas, não deixou de ser orientada tendo em vista obter acervo informativo que permitisse entender o comportamento no contexto de trabalho.

Um outro instrumento foi uma utilização, adaptada à idade da criança em estudo, do Self-Perception Profile for College Students de Susan Harter, que permite que as crianças se descrevam ao nível da sua autoestima, da competência escolar, da competência social, relação com os pais e nível de inteligência. Este teste permitiu medir o nível de autoestima em algumas valências (competências escolar e social, relação com os pais, inteligência) e analisar a importância que a criança atribui a estas diferentes áreas. Esta ferramenta, adotada em dezembro e em junho, permitiu definir o perfil que a criança tinha no início da intervenção e o que atingiu a final, bem como a sua perceção desta caraterística da personalidade.

\section{Sujeito do Estudo}

A escolha do sujeito do estudo recaiu sobre criança, que reagia com insegurança e receio perante situações novas ou de cada vez que alguém lhe pedia que realizasse uma tarefa. A partir das observações comportamentais e das reflexões feitas a partir delas, foram perscrutadas as causas principais das atitudes observadas, traçando-se então um plano de ação, obtida que foi a autorização da sua encarregada de educação.
Tendo em conta aquele apuramento, que concluiu pela pouca autonomia com que a criança havia sido criada, o plano de ação assentou em estímulos que levassem a criança a praticar atos que lhe trouxessem resultados e com isso ir aumentando os seus níveis de confiança. Neste contexto, emergiu a necessidade de lhe ser dado feedback positivo e transmitir confiança durante os tempos de maior "stress", como o momento do almoço, para a ajudar a ultrapassar esta insegurança. Em paralelo, foram concebidas intervenções em grande grupo, que promovessem o desenvolvimento da sua autoestima, através da aceitação das suas caraterísticas individuais e da exploração das suas emoções, do conhecimento da opinião que os colegas têm dela, da aceitação das suas dificuldades e enaltecimento das suas qualidades, compreendendo que todos somos diferentes. Estas atividades em grande grupo foram associadas a constantes intervenções individualizadas e retornos positivos. Com todas estas intervenções intencionais e com o apoio de colegas da sala, a criança começou a ter uma atitude mais positiva sobre si mesma, a sentir que faz parte de um grupo que a aceita com todas as suas caraterísticas, a perceber que o adulto a auxilia naquilo que se sentir mais insegura, e o seu comportamento mudou de forma favorável, evidenciando uma confiança nas suas capacidades. Com recurso ao instrumento supra-referido, foi possível verificar, não só, a evolução do nível de autoestima classificado pela própria criança (de $46 \%$ em dezembro para $80 \%$ em junho), como concluir que, atribuindo máxima importância aos diversos fatores comportamentais, a menor performance ou nível qualitativo em alguns deles, aprofundava a sua baixa autoestima.

Da triangulação dos dados resultantes da utilização destes diferentes instrumentos metodológicos puderam extrair-se algumas ilações fundamentais: a importância da observação dos comportamentos, o relevo da consciencialização da criança para os fatores que podem influenciar os níveis da autoestima, a atenção e dedicação do educador a este problema, a necessidade de trabalho individualizado e em grupo, tudo tendo em conta a concreta personalidade da criança e as razões que determinavam as suas inseguranças.

\section{Enquadramento Global}

Importa referir que a abordagem ao tema, teve como substrato o fundamento teórico da autoestima e do papel do educador, a perceção de que a intervenção deveria ser integrada de forma natural e imperceptível no projecto delineado para o grupo, a certeza da necessidade de apreender o ambiente familiar e as características da comunidade envolvente e a consciência de que a criança é um ser em formação.

No que tange à autoestima, antes pensava-se que era falta de humildade e egoísmo, mas hoje o conceito evoluiu, podendo caracterizar-se como um conjunto das atitudes do indivíduo para consigo mesmo, não sendo um estado constante, antes dinâmico, podendo alterar-se conforme as experiências pelas quais se vai passando. Por isso, a autoestima é educável, não nasce propriamente 
com a criança, embora esta, desde o nascimento está naturalmente recetiva aos estímulos que podem conduzir à valorização da autoestima ou à sua desvalorização. E revela-se sobretudo como sustentáculo de autoconfiança, fundamental para o relacionamento com os outros, para traçar objetivos cada vez mais desafiantes e ter capacidade para os prosseguir, para ser capaz de se dar aos outros e, dessa dádiva obter a sua própria realização.

Com autoestima, conseguimos testemunhar que é possível ultrapassar as dificuldades, aceitando que temos de errar, mas que não temos de ficar amarrados ao erro. Existem críticas construtivas e destrutivas, relevantes ou irrelevantes. $\mathrm{Na}$ sociedade atual todos se criticam mutuamente. A destrutiva visa somente condená-la e atacar a pessoa sem lhe deixar uma saída. A crítica construtiva dirige-se à ação em si e não à pessoa em concreto, favorece as relações pessoais e ajuda a melhorar e evoluir, não devendo ser vista de forma negativa. Saber elogiar, avaliar a situação, ponderar a mudança e escolher o momento certo em que seja adequado para que a crítica se torne realmente construtiva. "A auto-estima é ter confiança em si mesmo; mas não uma confiança vazia, puramente afetiva e sem fundamento objectivo, antes, uma confiança na própria capacidade" (Cabanas, 2009:107).

Por outro lado, e para se focar adequadamente a missão do educador, importa ter bem assimilado qual deva ser, hoje por hoje, o objetivo da educação, o sentido que faz ser educador. Temos todos a consciência de que assistimos a grandes e constantes mutações nos mais diversos domínios, afirmando-se a globalização e a divulgação instantânea como o paradigma da sociedade hodierna. De facto, a transmissão dos valores e a passagem do conhecimento ou dos saberes assumem, no seu modo e no conteúdo, toda uma nova perspetiva, num mundo em mudança permanente e acelerada. Esta está a pôr em causa a tradicional mundividência, a cadência de vida, o tipo e formas de relacionamento entre as pessoas, desde a escala mais diminuta da família (conceito este também em redefinição) até à escala mundial, o equilíbrio entre as comunidades e países. Do mesmo passo, o saber obtido pela instrução é cada vez mais efémero e ultrapassado, em que os saberes de hoje são amanhã relíquias. Tal implica uma diferente focagem da função educativa, agora orientada para que os seres humanos sejam livres e capazes de serem donos dos seus próprios destinos. Como sustenta Delors (1996:86), "mais do que nunca a educação parece ter, como papel essencial, conferir a todos os seres humanos a liberdade de pensamento, discernimento, sentimento e imaginação de que necessitam para desenvolver os seus talentos e permanecerem tanto quanto possível, donos do seu próprio destino"

Esta nova faceta ou diferente focagem da função educativa assume acrescida relevância desde os primórdios da formação da personalidade, sendo a fase do pré-escolar a que releva no contexto escolar. A esta luz, poder-se-ia ser-se tentado a concluir que, sendo tudo transitório e mutável, de nada vale aprender ou adquirir conhecimentos, ou que, se a informação está toda aí à disposição e de forma (quase) gratuita e a qualquer hora, na internet, nos "media", em outros meios eletrónicos de transmissão, que interesse tem a escola e o "intermediário" Educador. Será uma conclusão, no mínimo, precipitada e redutora. Se há época em que mais necessário e premente se mostra o educador, a escola, a educação, é a que vivemos. Preparar uma criança para as responsabilidades que o futuro vai acarretar constitui uma missão insubstituível do sistema educativo. A catequização teórica e prática de valores sólidos, sãos e consistentes, nesta ambiência do utilitarismo de curto prazo, a par da dotação de ferramentas que permitam uma adequação tempestiva, adequada e proficiente às alterações sucessivas, estão na charneira da missão educativa e do papel do Educador do pré-escolar. Criar curiosidade, desassombro e liberdade constitui o tripé axiomático que norteia e objetiva a formação educativa pré-escolar e, forçosamente, molda a missão do Educador. Nesta senda, a missão primeira do Educador é ensinar a criança a "aprender a aprender" - este será o seu sustentáculo que lhe permitirá responder às evoluções durante a sua vida - e a praticar em ambiente escolar, de forma intencionalmente educativa, os valores democráticos, de liberdade e de respeito pelo outro.

Sem que tal constitua qualquer desvalor do papel do educador, é importante ter presente que a família assume uma missão insubstituível no desenvolvimento da autoestima da criança -"Se a participação da família no ensino é necessária, é-o muito mais na educação de atitudes" (Alcantara 2000:83).

Para as crianças, os pais servem como modelos e existem várias caraterísticas das famílias que influenciam na autoestima das crianças. Os pais com baixa autoestima acabam por transmitir de forma indireta esta atitude para os seus filhos; de igual sorte, pais que são demasiado protetores, não deixando as crianças experimentarem, arriscarem e tomarem algumas decisões, tiram a responsabilidade aos filhos, não os fazem entender que só com esforço é que se pode alcançar as metas que se pretende; também as contínuas reprimendas transmitem uma imagem negativa dos próprios filhos, que, tantas vezes repetidas, acabam por contribuir para a construção de uma baixa autoestima. Daí que o amor e o incentivo criam a indispensável estrutura que dá esperança para viver e por isso, conduz à autoestima e à autoconfiança.

Como se disse, é de extrema importância ter em conta que não se deve atender apenas à criança sujeito, mas saber situá-la no seu meio, tendo atenção às vivências que tem experienciado, à família com quem vive e as suas caraterísticas sociais, económicas e culturais. Por isso, foi efectuado um levantamento de onde viviam, qual o percurso escolar anterior, a composição familiar, o nível literário dos pais, as suas profissões, a idiossincrasia da comunidade societária, ou seja, o universo interno e externo em que a criança se move.

A criança é um ser em formação, em todos os aspetos, físicos, emocionais e intelectuais. E, desde o embrião, mas de forma mais relacional, desde o nascimento, essa formação, sendo contínua, passa por fases ou estádios evolutivos, cada um com a sua marca mais distintiva, que, 
no entanto, varia conforme os diversos autores, salientando a faceta que mais releva para a sua visão. Todos são fundamentais para a construção da personalidade, que, depois, vai marcar toda a vida. Comos sustentam Gardner, H., Chen, J.,\& Moran, S., 2010:18 e 19), "não há dois seres humanos que possuam o mesmo perfil em suas qualidades e em suas limitações em termos de inteligência", destacando-se, em termos comportamentais, a inteligência interpessoal "capacidade de compreender as outras pessoas "(Goleman, 2009:59) - e a inteligência intrapessoal "capacidade correlativa para dentro" (ibidem). A sua combinação constitui a denominada inteligência emocional, que consiste em estar bem consigo mesmo e com os outros, conseguindo controlar emoções, sentimentos e afetos.

A psicologia do desenvolvimento apresenta-nos caraterísticas de uma criança padrão, mas é importante salientar que cada criança é uma criança, com as suas próprias necessidades e os seus interesses, fruto das experiências vividas, do meio em que se insere e também da sua própria personalidade. Como refere (Papalia et al, 2001:9) “(...) cada criança é semelhante às outras em alguns aspetos, mas é única em outros aspetos". Portanto, urge confrontar a teoria com a prática, ou seja, comparar o que os autores apontam para cada idade e o que se tem vindo a verificar com o grupo de crianças em que cada uma se insere.

\section{O Papel do Educador}

Imbuídas e habilitadas com estes fundamentais e orientadas por estes racionais, ficou mais clara, densificada e determinada a missão que, designadamente no campo da temática objecto, incumbe ao educador, que assume um papel, também ele essência- "A relação que o educador estabelece com cada criança, a forma como a valoriza e respeita, estimula e encoraja os seus progressos, contribuem para a auto-estima da criança" (Ministério da Educação, 1997: 52)

Como mencionado já, nenhuma criança nasce com autoestima congénita. A observação que dela os outros vão fazendo criará um clima favorável ou desfavorável a uma autoestima positiva. Por isso, a autoestima alimentase da consecução de pequenos êxitos no alcance ou superação dos objetivos que vão sendo traçados, por pequenos que sejam, e do reconhecimento pelos outros desse alcance. E reforça-se com a satisfação da partilha com os outros das suas capacidades e da ajuda que consegue transmitir.

Nestes dois parâmetros, melhor, na definição de objetivos, na condução da criança para os superar, na criação de condições para que a criança possa, perante os outros, fazer uso das suas capacidades, o contributo do educador revela-se de suprema importância. Pode até dizer-se que educar é sobretudo suscitar a auto-estima -"A auto-estima é o ingrediente vital para o êxito e felicidade das nossas vidas" (Tavares, 2004: 38).

\section{Conclusões}

Como principais conclusões, que os resultados alcançados com a acção desenvolvida corroboram, podemos sintetizar as seguintes asserções: a autoestima é um bem em si mesmo; gera autoconfiança e capacidade de enfrentar os desafios que se colocam; a alta autoestima cria um clima positivo conducente à felicidade e ao bemestar; a alta autoestima é uma característica que se vai adquirindo, desde a primeira infância; constrói-se e alimenta-se da superação com êxito dos objetivos que se vão traçando, com o reconhecimento pelos outros dessa realização; reforça-se de forma sustentável pela satisfação de ajudar os outros, partilhando com eles as capacidades, os conhecimentos ou com eles realizando tarefas conjuntas; a condução dos pais e dos educadores, no seu exemplo comportamental e na proporção de condições que permitam exercitar a autoestima, são essenciais para que a criança a adquira; a autoestima é, assim, educável, em qualquer etapa do desenvolvimento da criança, logo a partir do seu nascimento e há vários modos, métodos e técnicas para fomentar a criação de uma alta autoestima. Se o Educador descurar a tarefa de suscitar a autoestima, "abandona a tarefa prioritária" (Alcântara 2000:18).

\section{Referências}

Alcántara, J. A. (1991). Como educar a auto-estima Métodos. Estratégias. Lisboa: Editora Plátano.

Bell, J. (1997). Como realizar um projecto de investigação: um guia para a pesquisa em ciências sociais e da educação. Lisboa: Gradiva.

Cabanas, J. M. (2009). Lidar com crianças e jovens introvertidos: guia para pais, educadores e professores. Sintra: K Editora.

Delors (coord.) (1996) Educação um tesouro a descobrir: Relatório para a UNESCO da Comissão Internacional sobre Educação para o século XXI. Porto: Edições Asa.

Fachada, M. O. (2010). Psicologia das Relações Interpessoais. Lisboa: Sílabo Editora.

Gardner, H., Chen, J., Moran, S. \& Col.(2010). Inteligências múltiplas: ao redor do mundo. Porto Alegre: Artmed.

Goleman, D. (2009). Inteligência emocional. [S.1.] Temas e Debates e Círculo de Leitores.

Harter, S. (1993). Developmental changes in selfunderstanding across the 5 to 7 shift. In A. Sameroff \& M.Haith (Eds.), Reason and responsibility: The passage through childhood. Chicago: University of Chicago Press.

Ministério da Educação. (1997). Orientações Curriculares para a Educação Pré-Escolar. Lisboa: Ministério da Educação - Departamento de Educação Básica.

Papalia, D,. et al, (2001). O Mundo da Criança. Lisboa: McGraw-Hill de Portugal.

Tavares, M. G. (2004, Abril-Maio-Junho). Auto-estima para sermos mais felizes. Cadernos de educação de infância, $\mathrm{n}^{\circ} 70,38$.

Zabala, A. (2001). O construtivismo na sala de aula. Porto: Edições Asa. 